\title{
The Impact of PE Teachers' Leadership on Middle School Students
}

\author{
Minhyun Kim¹, Hyeonho Yu², \& Boung Jin Kang ${ }^{3}$ \\ 1 Sam Houston State University, Texas, USA \\ 2 Arizona State University, Arizona, USA \\ ${ }^{3}$ Elizabeth City State University, North Carolina, USA
}

\begin{abstract}
Physical education (PE) teachers' leadership plays a critical role in enhancing students' learning. Each PE teacher leadership style implies a critical meaning of how a class reaches its goals and objectives effectively. Transformational leadership initially was proposed by Burns (1978). Daft (2008) defined transformational leadership as "characterized by the ability to bring about significant change in followers and the organization" (p. 356). The expectancy value theory focuses on two critical aspects: an expectation of being successful in a current or distant task and the value placed on having a value for doing the task. The purpose of this study was to examine the effect of PE teachers' transformational leadership on middle school students' expectancy-value.
\end{abstract}

Keywords: leadership, PE Teacher, middle school students

\begin{tabular}{lr}
\hline Article History & Corresponding Author \\
Received 13 September 2020 & minhyun Kim \\
Accepted 10 October 2020 & shsu.edu \\
Published 31 January 2021 & Department of Kinesiology \\
Available online 19 February 2021 & College of Health Science \\
https://doi.org/10.47544/johsk.2021.2.1.35 & Sam Houston State University, Texas, USA \\
\hline
\end{tabular}

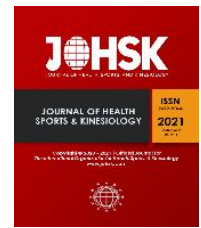

\section{Methods}

Transformational teaching questionnaire (Beauchamp et al., 2010) and expectancy-value questionnaire (Duncan \& Tammen, 1989) were employed for this study; a total of 16 items were used. The participants included 295 middle school students from three private middle schools located in the southwestern area in the USA and 262 questionnaires were used for the data analyses. Collected data were analyzed by descriptive, exploratory factor analysis and regression using the SPSS 25.

\section{Results}

According to single regression, transformational leadership had a positive impact on students' expectancy-value. Based on multiple regression, intellectual stimulation was a common factor that affected students' expectancyvalue positively.

\section{Journal of Health, Sports, \& Kinesiology | ISSN 2692-9864 | www.johsk.com}


| 2021 | Volume 2 | Issue 1 | The Journal of Health, Sports, and Kinesiology |

\section{Conclusion}

The results of the study support the importance of transformational leadership which used a means of enhancing middle school students' expectancy-value in PE. Moreover, this study indicated that transformational leadership facilitates teaching and students' learning in PE. Thus, it is recommended that PE teachers be able to understand and display appropriate leadership, in particular transformational leadership.

\section{Journal of Health, Sports, \& Kinesiology | ISSN 2692-9864 | www.johsk.com}

